\title{
When to use frovatriptan in migraine?
}

\author{
Peer Carsten Tfelt-Hansen
}

Received: 30 March 2011/Accepted: 4 April 2011 / Published online: 22 April 2011

(C) The Author(s) 2011. This article is published with open access at Springerlink.com

Sir,

In two cross-over randomized controlled trials (RCTs) published in the Journal of Headache and Pain, frovatriptan $2.5 \mathrm{mg}$ had a similar efficacy to that of rizatriptan $10 \mathrm{mg}$ [1] and almotriptan $12.5 \mathrm{mg}$ [2]. In both RCTs preference, the primary efficacy measure was quite comparable as were pain free and headache relief after $2 \mathrm{~h}$, and sustained pain free for $2-48 \mathrm{~h}[1,2]$. In contrast, in a systematic review of triptans [3n] the mean therapeutic gain (active minus placebo) for headache relief at $2 \mathrm{~h}$ was $19 \%$ (95\% CI 16-22\%) for frovatriptan $2.5 \mathrm{mg}$, whereas it was 33\% (95\% CI 31-35\%) for sumatriptan $100 \mathrm{mg}, 34 \%$ (95\% CI 30-37\%) for zolmitriptan $2.5 \mathrm{mg}, 36 \%$ (95\% CI $32-39 \%$ ) for rizatriptan $10 \mathrm{mg}$, and $27 \%$ (95\% CI 20-33\%) for almotriptan $12.5 \mathrm{mg}$. The superiority of sumatriptan $100 \mathrm{mg}$ versus frovatriptan $2.5 \mathrm{mg}$ was confirmed in a not fully published large $(n=1196)$ RCT in which the headache relief rates were 47 and $37 \%$, respectively [4, 5]. The recurrences rates for frovatriptan $(25 \%)$ and sumatriptan $(31 \%)$ were similar.

Migraine patients in these RCTs $[3,4,6]$ waited until the headache was moderate or severe whereas patients in the cross-over RCT were instructed to treat the migraine attack as early as possible [1,2]. Data on headache severity at the time of treatment were not reported in the papers on these two RCTs [1, 2]; a peculiar omission in papers on

P. C. Tfelt-Hansen $(\square)$

Department of Neurology, Danish Headache Center,

Glostrup Hospital, University of Copenhagen,

Glostrup, Denmark

e-mail: ptha@glo.regionh.dk acute migraine RCTs. In addition, patients not responding to triptans were excluded and the patients in the two crossover trials were, therefore, most likely less afflicted by migraine than the ones participating in the parallel group RCTs in which such patients were not excluded. The most likely reason for the comparable efficacy of frovatriptan and zolmitriptan [7], rizatriptan [1] and almotriptan [2] in these cross-over RCTs is, however, the very early use of test treatment.

In conclusion, frovatriptan is for moderate and severe headache not the triptan of first choice (therapeutic gain for frovatriptan is only 19 vs. $27-36 \%$ for other triptans, see above). However, if the migraine patients are able to treat their attacks very early, and have not demonstrated inadequate response to other triptans, then frovatriptan is most likely a good alternative to other triptans.

Yours sincerely

Peer Carsten Tfelt-Hansen

Open Access This article is distributed under the terms of the Creative Commons Attribution License which permits any use, distribution and reproduction in any medium, provided the original author(s) and source are credited.

\section{References}

1. Savi L, Omboni S, Lisotto C, Zanchin G, Ferrari MD, Zava D et al (2011) A double-blind, randomized, multicenter, Italian study of frovatriptan versus rizatriptan for the acute treatment of migraine. J Headache Pain 12:219-226

2. Bartolini M, Giamberardino MA, Lisotto C, Marteletti P, Moscato D, Panascia B et al (2011) A double-blind, randomized, multicenter, Italian study of frovatriptan versus almotriptan for the acute treatment of migraine. J Headache Pain. doi:10.1007/s10194-011-0325-5

3. Saxena PR, Tfelt-Hansen P (2006) Triptans, 5HT1B/1D agonists in the acute treatment of migraine. In: Olesen J, Goadsby PJ, 
Ramadan NM, Tfelt-Hansen P, Welch KMA (eds) The Headaches, 3rd edn. Lippincott Williams \& Wilkins, Philadelphia, pp 469-503

4. Tfelt-Hansen P (2008) Frovatriptan and data publication. Headache 48:1382-1383

5. Hutchison J, Pfaffenrath V, Geraud G (2007) A randomized, placebo-controlled, parallel-group trial of frovatriptan and sumatriptan for a single acute migraine attack. Eur J Neurol 14(Suppl. 1): 144
6. Ferrari MD, Roon KI, Lipton RB, Goadsby PJ (2001) Oral triptans (serotonin 5-HT (1B/1D) agonists) in the acute migraine treatment: a meta-analysis of 53 trials. Lancet 358:1668-1675

7. Tullo V, Allais G, Ferrari MD, Curone M, Mea E, Omboni S et al (2010) Frovatriptan versus zolmitriptan for the acute treatment of migraine: a double-blind, randomized, multicenter, Italian study. Neurol Sci 31(Suppl 1):S51-S54 